\title{
ANÁLISIS DE LA VARIACIÓN TEMPORAL Y ESPACIAL DE LA COBERTURA GLACIAR DEL NEVADO CAYAMBE, ECUADOR, MEDIANTE FOTOGRAFÍAS AÉREAS E IMÁGENES LANDSAT
}

\author{
ELVIA GALLEGOS CASTRO ${ }^{1}$, CORNELIA BRITO CHASILUISA ${ }^{1}$, DAVID SERRANO \\ GINÉ $^{2}$, REMIGIO GALÁRRAGA SÁNCHEZ ${ }^{3}$ \\ ${ }^{1}$ Escuela Politécnica Nacional, Ladron de Guevera E11-253, Quito 170517, Ecuador. \\ elvia.gallegosc@epn.edu.ec, elizabeth_lukas20@yahoo.com \\ ${ }^{2}$ Universitat Rovira i Virgili, Carrer de l'Escorxador, s/n, 43003 Tarragona \\ david.serrano@urv.cat \\ ${ }^{3}$ Desarrollo Sustentable Agua y Salud, Ecuador \\ corideas@gmail.com
}

\section{RESUMEN}

El presente trabajo determina la variación de la cobertura glaciar del nevado Cayambe (Ecuador), para el período 1978-2009 mediante dos fuentes de información complementarias. La primera consiste en fotografías aéreas (período 1978-1999); la segunda en imágenes satelitales Landsat (1979-2009). Los resultados revelan una ocupación de $23,85 \mathrm{~km}^{2}$ para el inicio del periodo y de $15,36 \mathrm{~km}^{2}$ para el final del mismo. El porcentaje de reducción es del $25,53 \%$ para los años analizados mediante fotografías aéreas y del $25,58 \%$ para los años estudiados a partir de imágenes de satélite. Estos valores confirman una tendencia a la reducción observada en otros glaciales equinocciales en el Ecuador, como el Iliniza Sur, Antisana, Cotopaxi y Chimborazo.

Palabras clave: Nevado Cayambe, glaciar, fotografías aéreas, imágenes LANDSAT, teledetección, aerofotogrametría.

TIME AND SPATIAL CHANGES IN NEVADO CAYAMBE GLACIER, ECUADOR, USING AERIAL PHOTOGRAPHS AND LANDSAT IMAGINERY

\section{ABSTRACT}

This study determines glacial coverage changes in nevado Cayambe (Ecuador), for the period 1978-2009, using two different but supplementary sources of information. The first one is aerial photographs (period 1978-1999); the second one is Landsat imagery (period 1979-2009). 
Gallegos Castro, E., Brito Chasiluisa,C. Serrano Giné, D., Galárraga Sánchez, R.. (2018): “Análisis de la variación temporal y espacial de la cobertura glaciar del nevado Cayambe, Ecuador, mediante fotografías aéreas e imágenes Landsat, GeoFocus (Artículos), no 22, p. 97-113. ISSN: 1578-5157 http://dx.doi.org/10.21138/GF.577

Results reveal $23.85 \mathrm{~km}^{2}$ of ice coverage at the beginning of the period and $15.36 \mathrm{~km}^{2}$ at the end. Reduction percentage is $25.53 \%$ for the years studied using aerial photographs and $25.58 \%$ for the years studied using remote sensing imagery. These figures support a trend to reduction observed in other Ecuadorian equinoctial glaciers such as Iliniza Sur, Antisana, Cotopaxi and Chimborazo.

Keywords: Nevado Cayambe, glacier, aerial photographs, LANDSAT images, remote sensing, aero Photogrammetry

\section{Introducción}

Los glaciares tropicales andinos constituyen indicadores del cambio climático de gran interés e importancia, a causa de su elevada sensibilidad a las variaciones ambientales (Rabatel et al., 2013; Rabatel et al., 2017; Drenkhan et al., 2018) y, particularmente, climáticas (Rowan, 2018). Distintos estudios en la región señalan una clara tendencia a la reducción de las cubiertas glaciares de los Andes (Rabatel et al., 2013; Małecki et al., 2018). En el Nevado Santa Isabel (Colombia) la extensión glaciar actual es inferior en un $90 \%$ a la existente en la Pequeña Edad del Hielo, un $62 \%$ menor a la de mitad del siglo pasado y dos terceras partes más pequeña de la existente a mitad de la década de 1990 (Rabatel et al., 2017). En la Cordillera Blanca del Perú la reducción acaecida entre 1975 y 2016 se cifra en un $33.5 \%$ (Veetil, 2018) y en el sistema Vilcanota-Urubamba, en la región de Cusco, Drenkhan et al. (2018) cifran la disminución en un 37.3 \% para el periodo 1988-2016, lo que significa más de un $1 \%$ anual. Otros trabajos reportan tendencias similares para el conjunto de la región (Rabatel et al., 2013) y existe consenso en afirmar un retroceso notorio y acelerado que se ha incrementado de manera generalizada a partir de la década de 1980 (Cáceres, 2010).

A pesar de los patrones de reducción existentes (Rabatel et al., 2013; Rabatel et al., 2017), se conoce una variabilidad espaciotemporal my grande (Falaschi et al., 2017). Algunas proyecciones sugieren una reducción en la tasa de retroceso de los glaciares, que en algunos sistemas podría estar produciéndose en la actualidad (Drenkhan et al., 2018), mientras que otras prevén la progresiva reducción y final desaparición de los casquetes (Yarleque et al., 2018). La variabilidad de casuísticas es muy elevada, tanto en ámbitos locales como regionales. En los glaciares andinos australes las tasas de reducción recientemente estudiadas son menos negativas que en periodos anteriores (Falaschi et al., 2017), y Drewes et al. (2018) subrayan la importancia de las dinámicas regionales y el comportamiento distinto que muestran los glaciares. En general, se admite que en los Andes equinocciales solo pervivirán los glaciares situados en cotas más elevadas hasta mitad de siglo, y de manera más reducida que en la actualidad (Rabatel et al., 2017).

En Ecuador, la cobertura nival y glacial de numerosos nevados ha ido mermando de manera continuada en los últimos años, y numerosas cimas antes coronadas por glaciares ahora muestran roquedos, canchales, morrenas y otras geoformas propias de ambientes fríos (Francou et al., 2011).

Ecuador no dispone de una cartografía exhaustiva ni de estudios completos sobre sus coberturas glaciares, pero existen esfuerzos importantes para algunos de sus nevados: Chimborazo (Jordan et al, 2005), Iliniza Sur (Febres, 2007), Carihuayrazo (Cáceres, 2010), Antisana (Collet, 2010) y Cotopaxi (Jaramillo, 2012). La falta de información acerca de los cambios ocurridos en las masas glaciares no permite tener una visión prospectiva de conjunto para los Andes equinocciales, y ello compromete el buen conocimiento de estos ecosistemas. Trabajos como los de Małecki et al. (2018) en la reducción de glaciares tropicales y estudios prospectivos como los desarrollados en 
Gallegos Castro, E., Brito Chasiluisa,C. Serrano Giné, D., Galárraga Sánchez, R.. (2018): “Análisis de la variación temporal y espacial de la cobertura glaciar del nevado Cayambe, Ecuador, mediante fotografías aéreas e imágenes Landsat, GeoFocus (Artículos), no 22, p. 97-113. ISSN: 1578-5157 http://dx.doi.org/10.21138/GF.577

glaciares representativos, como el Quelccaya (Yarleque et al. 2018), demuestran la necesidad de recabar más información sobre el comportamiento de los glaciares tropicales, así como la necesidad de ampliar el estudio de sistemas glaciares a un mayor número de nevados.

En este artículo se genera información sobre los cambios en la cobertura glaciar del nevado Cayambe. En concreto, se detecta, cuantifica y localiza en contexto el cambio sufrido en la cobertura glaciar de este volcán en las últimas tres décadas mediante dos fuentes de información diferentes, fotografías aéreas e imágenes satelitales, y se contribuye a generar conocimiento sobre los glaciares tropicales andinos.

\section{2. Área de estudio}

El nevado Cayambe se encuentra ubicado en la Cordillera Central de los Andes (Figura 1), en la provincia de Pichincha, al noreste de la ciudad de Quito $\left(0^{\circ} 1^{\prime} 30^{\prime}\right.$ 'N, $77^{\circ} 59^{\prime} 13,2^{\prime}$ ') y en el mismo contexto regional que otras elevaciones andinas de mayor renombre como el Chimborazo $(6.263 \mathrm{~m})$ o el Cotopaxi $(5.897 \mathrm{~m})$. Con una elevación de $5.790 \mathrm{~m}$, el Cayambe es la tercera montaña más elevada del Ecuador, y el único glaciar del planeta cruzado por la línea equinoccial.

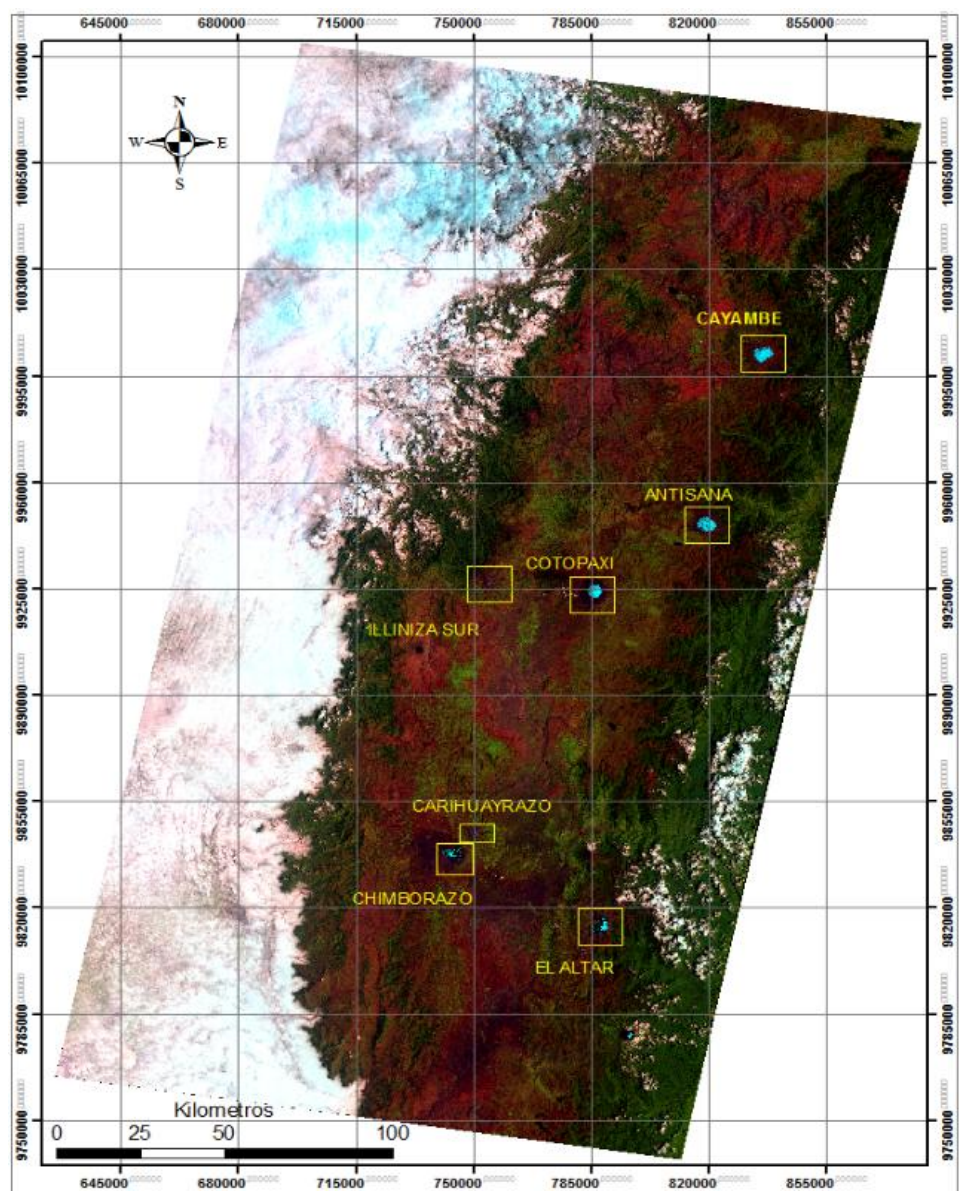

Figura 1. Localización del nevado Cayambe en el contexto de los Andes equinocciales. 
Gallegos Castro, E., Brito Chasiluisa,C. Serrano Giné, D., Galárraga Sánchez, R.. (2018): “Análisis de la variación temporal y espacial de la cobertura glaciar del nevado Cayambe, Ecuador, mediante fotografías aéreas e imágenes Landsat, GeoFocus (Artículos), no 22, p. 97-113. ISSN: 1578-5157 http://dx.doi.org/10.21138/GF.577

Sobre los $4.800 \mathrm{~m}$ está cubierto por un casquete glaciar que ocupa una extensión aproximada de $15 \mathrm{~km}^{2}$ y cuyo espesor, a pesar de ser variable, se estima entre 30 y $50 \mathrm{~m}$ en la cumbre (Samaniego et al., 2004). La cubierta glaciada presenta una marcada disimetría: así, en el flanco oriental las lenguas del glaciar llegan hasta los $4.400 \mathrm{~m}$, mientras que en el flanco occidental esta cota se sitúa entre los 4.800 y los $5.000 \mathrm{~m}$. Esta diferencia se explica por las dinámicas atmosféricas de los Andes centrales, que marcan una clara distinción entre los tipos de clima de la vertiente occidental y los de la vertiente oriental de la cordillera. En efecto, la vertiente oriental, o amazónica, produce un efecto barrera a las masas de aire cargadas de humedad provenientes de la cuenca amazónica, que precipitan una gran cantidad de humedad sobre los flancos de las laderas este de la Cordillera; por el contrario, la vertiente oeste, o del Pacífico, es mucho más seca y menos propensa a generar precipitaciones orogénicas (Cáceres, 2010).

La parte occidental de este complejo se caracteriza por pendientes suaves y valles profundos, producidos por la erosión glaciar cuaternaria; la sección oriental, por su parte, ofrece pendientes más acentuadas y su topografía es más accidentada. Desde el oeste, el nevado Cayambe tiene forma trapezoidal con pendientes acusadas y cima plana; por el contrario, si se observa desde el norte se trata de una elevación rugosa y quebrada, compuesta por múltiples cumbres (Samaniego, 2004).

En lo que respecta al clima, las temperaturas oscilan entre los $0^{\circ}$ y $\operatorname{los} 20^{\circ}$, según altitud y exposición, con poca variabilidad interanual pero elevada variabilidad diaria; se conoce una gran diferencia térmica entre el día y la noche y entre días cubiertos y descubiertos. La humedad relativa casi siempre es mayor al $80 \%$ en las inmediaciones del glaciar, pero desciende de manera notoria a medida que se incrementa su lejanía, particularmente en la vertiente oeste. Las precipitaciones registradas son variables durante todo el año, y los totales anuales varían entre los 800 y los 2000 $\mathrm{mm}$, dependiendo de la altitud y la exposición. Como en todo contexto equinoccial, la noción de invierno y verano carece del sentido que tiene en latitudes altas, y debe canjearse por la de períodos ligeramente más húmedos (enero - mayo) que otros. Los caudales de alta montaña se registran prácticamente constantes a lo largo de todo el año, tanto por las contribuciones en forma de precipitación como por aquellas provenientes del deshielo (Montero, 2010). El nevado Cayambe se encuentra drenado por dos grandes sistemas fluviales, dirigidos hacia el occidente por el río Pisque y hacia el oriente por el río Salado. Entre los valles de la parte occidental destaca el valle drenado por el río Blanco, que desciende de las cumbres del Nevado, atraviesa la ciudad de Cayambe, y desemboca en el río San José, que a partir de ese punto pasa a denominarse Granobles (Samaniego, 2004). Las actividades productivas son principalmente de carácter agrícola y ganadero, se localizan en el entorno de la población de Cayambe y se conoce que precisan importantes aportes de agua para su desarrollo (Valencia et al., 2014).

Existen escasas pero interesantes referencias históricas a la extensión de la masa glaciada del Cayambe. Montero (2010) recoge distintos testigos y, juntamente con depósitos morrénicos y otras geoformas propias de zonas frías, se puede trazar una extensión que supera los actuales límites del hielo.

\section{Materiales, datos y métodos}

Para obtener la variación espacio-temporal de la cobertura glaciar del nevado Cayambe, se usaron fotografías aéreas e imágenes satelitales. 
Gallegos Castro, E., Brito Chasiluisa,C. Serrano Giné, D., Galárraga Sánchez, R.. (2018): “Análisis de la variación temporal y espacial de la cobertura glaciar del nevado Cayambe, Ecuador, mediante fotografías aéreas e imágenes Landsat, GeoFocus (Artículos), no 22, p. 97-113. ISSN: 1578-5157 http://dx.doi.org/10.21138/GF.577

\subsection{Fotografías aéreas}

Para realizar el análisis con fotografías aéreas se recolectaron y seleccionaron fotogramas de los años 1978 y 1999. De acuerdo a criterios de cobertura del área de estudio y calidad de las imágenes, se trabajó con 15 fotografías a escala 1:60.000 en el centro de la imagen. La contextualización de las imágenes se realizó definiendo los datos correspondientes a la orientación interna y externa de cada fotografía para, posteriormente, realizar la aerotriangulación de cada imagen (Martín, 1999).

Se construyó un modelo digital del terreno (MDT) a partir de las curvas de nivel y los puntos acotados de las cuatro cartas topográficas, a escala 1:50.000, que comprenden el área de estudio. El resultado fueron ortofotografías con una resolución de $60 \mathrm{~m}$ de píxel. Para el cálculo de la interpolación se utilizó el algoritmo "vecino más cercano", que consiste en medir la distancia entre cada entidad y la entidad vecina más cercana, para posteriormente calcular el promedio de todas las distancias de vecinos más cercanos. Este algoritmo considera que la relación del vecino más cercano promedio se deriva de la distancia promedio observada dividida por la distancia promedio esperada en una distribución hipotética aleatoria, y se conoce que es adecuado para interpolar superficies rugosas o con cambios topográficos bruscos (Mitchell, 2005).

Las ortofotos resultantes se organizaron en mosaico para una mejor comprensión del área de estudio. Seguidamente se inició la clasificación automática de las cubiertas del suelo (Fernández, 2000), que se precisó en tres grandes clases: glaciar, suelo desnudo y vegetación, mediante el software ERDAS. Las imágenes obtenidas para ambos años presentaban un efecto sal y pimienta (Chuvieco, 1999), que se retiró realizando una operación de vecindad, con seis iteraciones, hasta obtener una imagen homogénea.

Después de realizar la clasificación de las cubiertas se procedió a cortar la imagen para enfocarse en la zona de interés. Se realizó una reclasificación de cubiertas para un mejor funcionamiento interno del programa y, posteriormente, una conversión a formato vectorial. Con el programa ERDAS se revisó manualmente el vector resultante y se verificaron los límites de las entidades con las cubiertas existentes en la ortofotografía original. Esta revisión detallada permitió la categorización y cuantificación del glaciar de manera pormenorizada. En ciertas áreas, el glaciar se encontraba cubierto por detritos morrénicos, depósitos eólicos, bloques de caída libre o derrubios de distinto diámetro, dando lugar a que la masa glaciada ofreciera aspecto morrénico cuando, en realidad, se trataba de hielo parcialmente cubierto de clastos. Este fenómeno, que no es extraño en los glaciares poco activos o en recesión, trajo elevado número de problemas a la hora de definir los límites de las ocupaciones. Los factores que ayudaron a definir adecuadamente cada clase fueron las grietas y estrías que forman parte del glaciar, así como los escurrimientos de agua que salen de la base del mismo. Este procedimiento permitió detectar puntos concretos en el interior del glaciar donde no existía cubierta glaciada sino afloramiento rocoso, tal como sucede en aquellos casquetes sobre topografías quebradas o de gran contraste topográfico. Finalmente, se cuantificó el área ocupada estrictamente por hielo mediante el programa ArcGIS 10.0. 
Gallegos Castro, E., Brito Chasiluisa,C. Serrano Giné, D., Galárraga Sánchez, R.. (2018): “Análisis de la variación temporal y espacial de la cobertura glaciar del nevado Cayambe, Ecuador, mediante fotografías aéreas e imágenes Landsat, GeoFocus (Artículos), no 22, p. 97-113. ISSN: 1578-5157 http://dx.doi.org/10.21138/GF.577

\subsection{Imágenes satelitales}

Las imágenes satelitales Landsat se descargaron del sitio web EarthExplorer del servicio Geológico de los Estados Unidos. Se trabajó con la fila 10 columna 60, en una escena de más de $30.000 \mathrm{~km}^{2}$, dentro de la cual se halla la zona del nevado Cayambe.

De un total de 92 imágenes de satélite (período 1977-2013) procesadas en el Laboratorio de Aerofotogrametría y Sensores Remotos (LAfSER) de la Escuela Politécnica Nacional, únicamente seis imágenes reunieron calidad suficiente para su análisis. En concreto se trabajó con imágenes de 1979, 1991, 1999, 2002 y 2009 (dos imágenes) de los sensores MSS, TM y ETM+. Distintos elementos afectaron la selección final de dichas imágenes, entre los que cabe destacar la fecha de toma, la cobertura de nubes (\%), el grado de procesamiento geométrico y la superficie visible del glaciar (\%). De entre todos estos aspectos, el que recibió mayor consideración fue el temporal, pues la identificación de campos de nieve, de carácter efímero, como cubiertas glaciares entraña el riesgo de incrementar por comisión la superficie real del área estudiada (Racoviteanu et al., 2008). Por ello se buscaron los meses de menor precipitación, para evitar en lo posible cubiertas nivosas de carácter provisional; por el mismo motivo, y a causa de la acumulación de nieve en la sección noroeste y a la pobre resolución espacial de las imágenes, se decidió no incluir este sector en el estudio del conjunto para, así, no afectar el cálculo final de superficies.

Las imágenes Landsat pasaron por el siguiente pre-procesamiento: corrección geométrica (únicamente necesaria para la imagen de 1979; se realizó tomando 18 puntos de control de la imagen de 1991), corrección atmosférica, cálculo del índice de normalización diferencial de nieve para 1991, 1999 y 2002 (se obtuvieron valores de 0,4 a 0,95), clasificación no supervisada, reclasificación, vectorización, delimitación manual, medición de áreas y cálculo del porcentaje de retroceso. Para el tratamiento de las imágenes se utilizaron los programas ENVI y ArcGIS 10.0.

\subsection{Clasificación de cubiertas}

La clasificación de las cubiertas del suelo merece especial atención (Fernández, 2000). Se distinguieron tres grandes clases: glaciar, suelo desnudo y vegetación. La clase glaciar hace referencia a aquellos espacios cubiertos por hielo; la clase suelo desnudo a aquellas superficies ocupadas por morrenas, canchales, escarpes rocosos y afloramientos de roca o suelo desnudo; y la clase vegetación a aquellas superficies cubiertas por vegetación herbácea, ya fuera compacta o dispersa, herbácea o rastrera. Se emplearon distintos indicadores de apoyo para detectar y diferenciar la ocupación del suelo, entre los que cabe destacar el MDT, el mapa de pendientes y el de orientaciones (Felicísimo, 1994). También se realizaron seis campañas de campo para identificar el glaciar y su contorno de la manera más detallada posible, así como para verificar datos.

Finalmente, conviene notar aquí la importancia de los estudios de dinámicas de ocupación del suelo, particularmente en altas montañas tropicales, que en Latinoamérica no son tan habituales como en otros contextos regionales (Galicia y García-Romero, 2007; Tovar et al., 2013). El estudio de los cambios en las cubiertas del suelo en latitudes intertropicales es importante por la diversidad de orientaciones, gradientes de temperatura y procesos que se desarrollan en estos ecosistemas, así como las implicaciones que se derivan tanto en ámbitos socioeconómicos como biofísicos (Smethurts 2000). 
Gallegos Castro, E., Brito Chasiluisa,C. Serrano Giné, D., Galárraga Sánchez, R.. (2018): "Análisis de la variación temporal y espacial de la cobertura glaciar del nevado Cayambe, Ecuador, mediante fotografías aéreas e imágenes Landsat, GeoFocus (Artículos), no 22, p. 97-113. ISSN: 1578-5157 http://dx.doi.org/10.21138/GF.577

\section{Resultados}

Los resultados obtenidos mediante el uso de fotografías aéreas para el año 1978 señalan un valor de $23,85 \mathrm{~km}^{2}$ de cobertura glaciar y para el año 1999 una cobertura de $17,76 \mathrm{~km}^{2}$ (Tabla 1). Ello se traduce en un retroceso entre el periodo inicial y el periodo final de $25,53 \%$, es decir, una tasa anual del $1,21 \%$.

Tabla 1. Superficie del glaciar, mediante fotografías aéreas

\begin{tabular}{|l|c|}
\hline \multicolumn{1}{|c|}{ Año } & Superficie $\mathbf{( k m}^{\mathbf{2}} \mathbf{)}$ \\
\hline 1978 & 23,85 \\
\hline 1999 & 17,76 \\
\hline
\end{tabular}

Fte.: Elaboración propia a partir de fotografías aéreas.

Mediante el procesamiento de las imágenes satelitales Landsat para el período 1979-2009, se obtuvo un retroceso del glaciar del $25,58 \%$, lo que significa una tasa de retroceso de $0,176 \mathrm{~km}^{2} /$ año (Tabla 2).

Tabla 2. Superficie del glaciar, mediante imágenes satelitales

\begin{tabular}{|l|c|c|}
\hline Año & Superficie $\mathbf{( k m}^{\mathbf{2}} \mathbf{)}$ & Porcentaje de retroceso \\
\hline 1979 & 20,64 & --- \\
\hline 1991 & 19,32 & 6,40 \\
\hline 1999 & 17,94 & 13,08 \\
\hline 2002 & 16,51 & 20,01 \\
\hline 2009 & 15,36 & 25,58 \\
\hline
\end{tabular}

Fte.: Elaboración propia a partir de imágenes satelitales.

El análisis combinado de las fotografías aéreas y las imágenes satelitales permite seguir la dinámica de la cubierta nivo-glaciar del Cayambe para el periodo 1978-2009 (Figura 2).

Adicionalmente, se delimitaron cuatro zonas tomando como punto central la cumbre del nevado, y se trazaron 19 lenguas glaciares siguiendo las elevaciones topográficas y la estructura general del relieve, definidas a partir del MDT. Al igual que en otras experiencias en glaciares ecuatorianos (Jordan et al., 2005), se tomó como punto de origen las dos elevaciones de mayor importancia: una primaria de $5.790 \mathrm{~m}$ y otra secundaria de $5.477 \mathrm{~m}$ (Figura 3). 
Gallegos Castro, E., Brito Chasiluisa,C. Serrano Giné, D., Galárraga Sánchez, R.. (2018): “Análisis de la variación temporal y espacial de la cobertura glaciar del nevado Cayambe, Ecuador, mediante fotografías aéreas e imágenes Landsat, GeoFocus (Artículos), no 22, p. 97-113. ISSN: 1578-5157 http://dx.doi.org/10.21138/GF.577

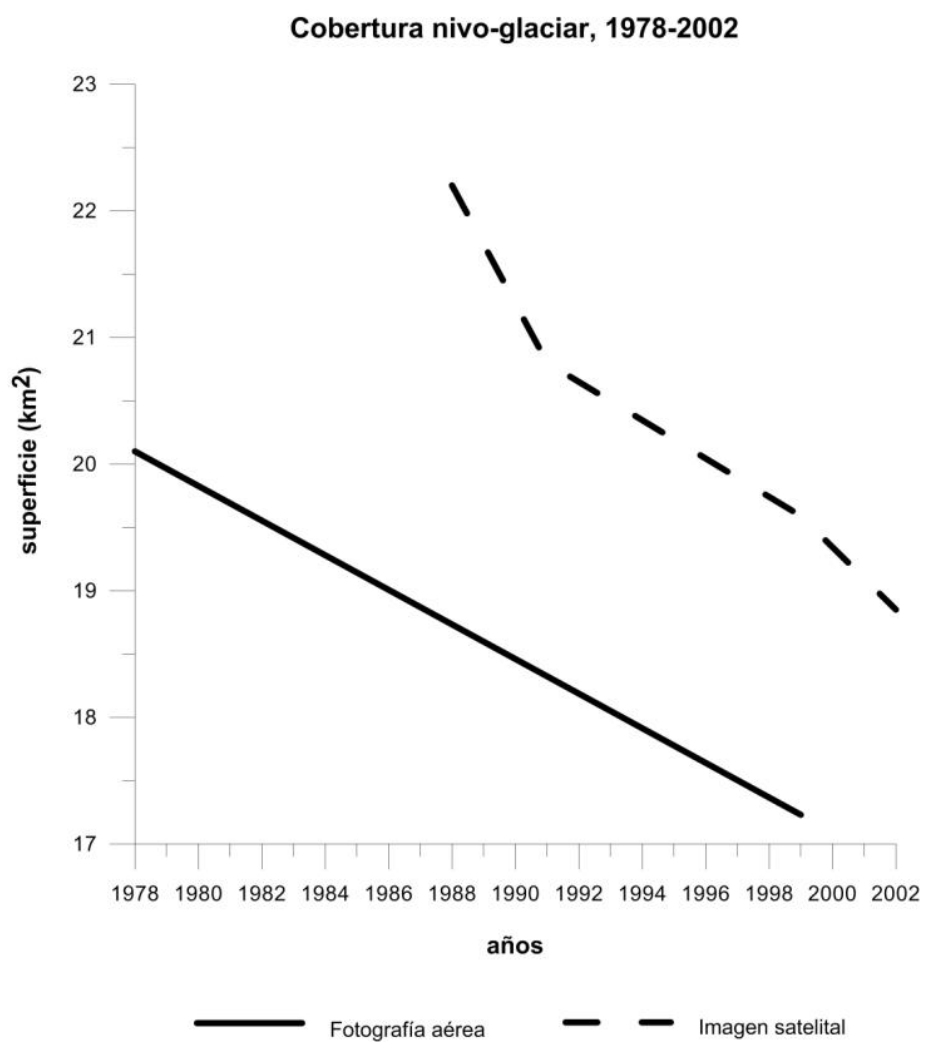

Figura 2. Evolución de la cubierta glaciar (1978-2009).
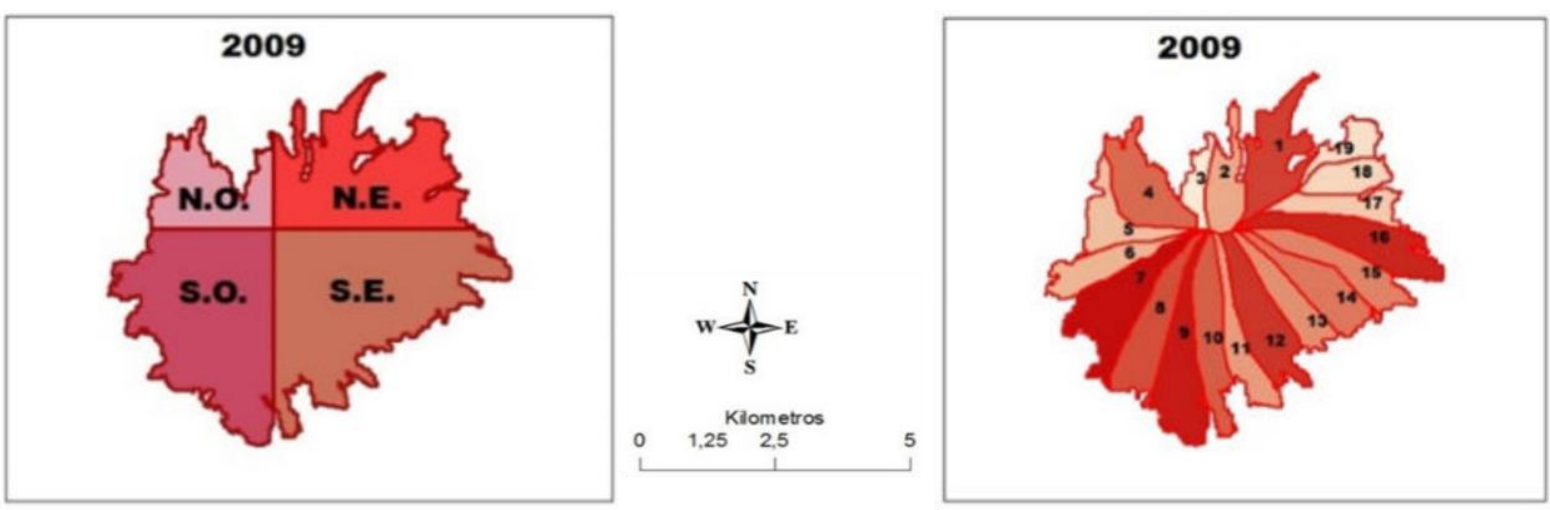

Figura 3. Zonas y lenguas del nevado Cayambe, año 2009.

Los resultados de las cuatro zonas delimitadas muestran que entre 1979 y 2009 la zona suroeste del nevado retrocedió un $0,80 \%$ anual; la zona sureste, un 1,03\% anual; la noroeste, un $0,5 \%$ y la noreste, un $0,77 \%$. Los resultados indican que la zona sureste del glaciar es la que mayor retroceso ha tenido, continuando por la suroeste (Tabla 3). 
Gallegos Castro, E., Brito Chasiluisa,C. Serrano Giné, D., Galárraga Sánchez, R.. (2018): “Análisis de la variación temporal y espacial de la cobertura glaciar del nevado Cayambe, Ecuador, mediante fotografías aéreas e imágenes Landsat, GeoFocus (Artículos), no 22, p. 97-113. ISSN: 1578-5157 http://dx.doi.org/10.21138/GF.577

Tabla 3. Retroceso por zonas

\begin{tabular}{|l|c|c|c|c|}
\hline \multicolumn{1}{|c|}{ Año } & \multicolumn{4}{|c|}{ Superficie $\mathbf{( k m}^{2}$ ) } \\
\hline & SO & SE & NO & NE \\
\hline 1979 & 6,19 & 7,82 & 1,99 & 4,64 \\
\hline 1991 & 5,48 & 7,37 & 2,09 & 4,38 \\
\hline 1999 & 5,49 & 6,63 & 1,97 & 3,86 \\
\hline 2002 & 5,11 & 5,38 & 2,06 & 3,96 \\
\hline 2009 & 4,71 & 5,40 & 1,69 & 3,56 \\
\hline \% de retroceso & 23,96 & 30,97 & 14,88 & 23,22 \\
\hline
\end{tabular}

Fte.: Elaboración propia a partir de imágenes satelitales.

En cuanto a los resultados de las 19 lenguas glaciares (Tabla 4), los porcentajes de retroceso calculados se encuentran entre el 4 y el $46 \%$. Cuatro lenguas glaciares $(9,7,10$ y 15) ubicadas al sur del glaciar presentan una tasa de retroceso de $0,02 \mathrm{~km}^{2} / a n ̃ o$, que es el mayor valor en comparación a las demás lenguas del glaciar. En segundo lugar se registra una tasa de retroceso de

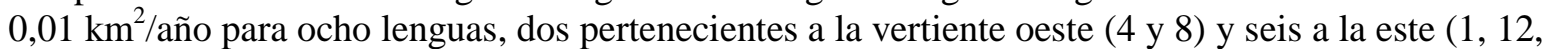
$13,14,17$ y 19). El tercer valor es de $0,005 \mathrm{~km}^{2} /$ año, para la lengua 16 , que se encuentra en la sección sureste del glaciar. Se calculó una tasa de $0,004 \mathrm{~km}^{2} /$ año para tres lenguas glaciares, dos del este (11 y 18) y una del noroeste (5). Los valores de $0,003 \mathrm{~km}^{2} / a$ ño, $0,002 \mathrm{~km}^{2} /$ año y $0,001 \mathrm{~km}^{2} / \mathrm{año}$ pertenecen a las lenguas 3, 2 y 6 respectivamente $(6$ y 3 se encuentran en la sección oeste y 2 en la noreste).

Tabla 4. Retroceso por lenguas (I)

\begin{tabular}{|c|c|c|c|c|c|c|c|c|c|c|}
\hline & \multicolumn{10}{|c|}{ Superficie $\left(\mathbf{k m}^{2}\right)$} \\
\hline Año & 1 & 2 & 3 & 4 & 5 & $\overline{6}$ & 7 & 8 & 9 & 10 \\
\hline 1979 & 1,31 & 0,71 & 0,40 & 1,21 & 0,76 & 0,66 & 1,80 & 1,19 & 1,81 & 1,49 \\
\hline 1991 & 1,33 & 0,72 & 0,51 & 1,17 & 0,68 & 0,65 & 1,60 & 1,10 & 1,45 & 1,26 \\
\hline 1999 & 1,20 & 0,64 & 0,41 & 1,12 & 0,70 & 0,65 & 1,56 & 1,22 & 1,37 & 1,20 \\
\hline 2002 & 1,25 & 0,73 & 0,42 & 1,21 & 0,68 & 0,60 & 1,47 & 1,08 & 1,26 & 1,05 \\
\hline 2009 & 1,04 & 0,64 & 0,32 & 0,99 & 0,63 & 0,63 & 1,21 & 1,02 & 1,15 & 1,00 \\
\hline $\begin{array}{l}\% \text { de } \\
\text { retroceso }\end{array}$ & 20,10 & 9,39 & 21,52 & 17,80 & 17,51 & 3,75 & 32,83 & 14,30 & 36,69 & 32,72 \\
\hline $\begin{array}{l}\text { Tasa de } \\
\text { retroceso } \\
(\% \text { año })\end{array}$ & 0,7 & 0,3 & 0,7 & 0,6 & 0,6 & 0,1 & 1,1 & 0,5 & 1,2 & 1,1 \\
\hline $\begin{array}{l}\text { Tasa de } \\
\text { retroceso } \\
\left(\mathrm{km}^{2} / \mathrm{año}\right)\end{array}$ & 0,0087 & 0,0022 & 0,0029 & 0,0072 & 0,0045 & 0,0008 & 0,0197 & 0,0057 & 0,0222 & 0,0163 \\
\hline
\end{tabular}

Fte.: Elaboración propia a partir de imágenes satelitales. 
Gallegos Castro, E., Brito Chasiluisa,C. Serrano Giné, D., Galárraga Sánchez, R.. (2018): “Análisis de la variación temporal y espacial de la cobertura glaciar del nevado Cayambe, Ecuador, mediante fotografías aéreas e imágenes Landsat, GeoFocus (Artículos), no 22, p. 97-113. ISSN: 1578-5157 http://dx.doi.org/10.21138/GF.577

Tabla 4. Retroceso por lenguas (II)

\begin{tabular}{|l|c|c|c|c|c|c|c|c|c|}
\hline & \multicolumn{7}{|c|}{ Superficie $\left.\mathbf{k m}^{\mathbf{2}}\right)$} \\
\hline Año & $\mathbf{1 1}$ & $\mathbf{1 2}$ & $\mathbf{1 3}$ & $\mathbf{1 4}$ & $\mathbf{1 5}$ & $\mathbf{1 6}$ & $\mathbf{1 7}$ & $\mathbf{1 8}$ & $\mathbf{1 9}$ \\
\hline 1979 & 0,77 & 1,47 & 0,99 & 1,11 & 1,43 & 1,27 & 0,89 & 0,62 & 0,72 \\
\hline 1991 & 0,79 & 1,35 & 1,00 & 1,18 & 1,04 & 1,53 & 0,83 & 0,52 & 0,61 \\
\hline 1999 & 0,75 & 1,27 & 0,87 & 1,12 & 0,99 & 1,25 & 0,67 & 0,51 & 0,44 \\
\hline 2002 & 0,67 & 1,12 & 0,71 & 0,84 & 0,89 & 0,94 & 0,63 & 0,50 & 0,45 \\
\hline 2009 & 0,65 & 1,07 & 0,68 & 0,87 & 0,84 & 1,14 & 0,59 & 0,51 & 0,38 \\
\hline $\begin{array}{l}\% \\
\text { retroceso }\end{array}$ & 16,34 & 27,66 & 31,16 & 21,95 & 41,66 & 10,69 & 34,10 & 17,91 & 46,84 \\
\hline $\begin{array}{l}\text { Tasa } \\
\text { retroceso } \\
\text { año) }\end{array}$ & 0,5 & 0,9 & 1,0 & 0,7 & 1,4 & 0,4 & 1,1 & 0,6 & 1,6 \\
\hline $\begin{array}{l}\text { Tasa } \\
\begin{array}{l}\text { retroceso } \\
\text { (km²/año) }\end{array}\end{array}$ & 0,0042 & 0,0136 & 0,0103 & 0,0081 & 0,0199 & 0,0045 & 0,0101 & 0,0037 & 0,0113 \\
\hline
\end{tabular}

Fte.: Elaboración propia a partir de imágenes satelitales.

\section{Discusión}

\subsection{Aspectos temáticos}

A partir del procesamiento de las fotografías aéreas (1978-1999) y de las imágenes de satélite (1978-2009) se ha obtenido un retroceso del glaciar del 25,53\% y del 25,58\%, respectivamente. Estos dos valores, a pesar de diferir en diez años, manifiestan una tendencia a la reducción.

La zona con mayor retroceso corresponde a la zona sur, tal como se observa en la Figura 4 y 5. La distribución de las zonas con mayor merma de cobertura glaciar responde a distintas razones que todavía no se encuentran suficientemente trabajadas, pero la topografía existente y las condiciones microclimáticas han de considerarse de manera particularmente especial. Ello se demuestra con el hecho que las mayores tasas de reducción $\left(0,02 \mathrm{~km}^{2} /\right.$ año $)$ tienen tendencia a localizarse en la vertiente oeste del volcán, más seca y expuesta a las dinámicas atmosféricas del Pacífico. No queda claro, no obstante, si el ritmo de retroceso se encuentra afectado de manera notoria por otros aspectos, como por ejemplo la pérdida de superficie y volumen de hielo, la distancia y características de la zona de fractura, el balance de masa, los vientos dominantes y la ablación, así como la influencia del albedo, que en latitudes bajas se conoce de importancia especialmente significativa. 
Gallegos Castro, E., Brito Chasiluisa,C. Serrano Giné, D., Galárraga Sánchez, R.. (2018): "Análisis de la variación temporal y espacial de la cobertura glaciar del nevado Cayambe, Ecuador, mediante fotografías aéreas e imágenes Landsat, GeoFocus (Artículos), $n^{\circ}$ 22, p. 97-113. ISSN: 1578-5157 http://dx.doi.org/10.21138/GF.577

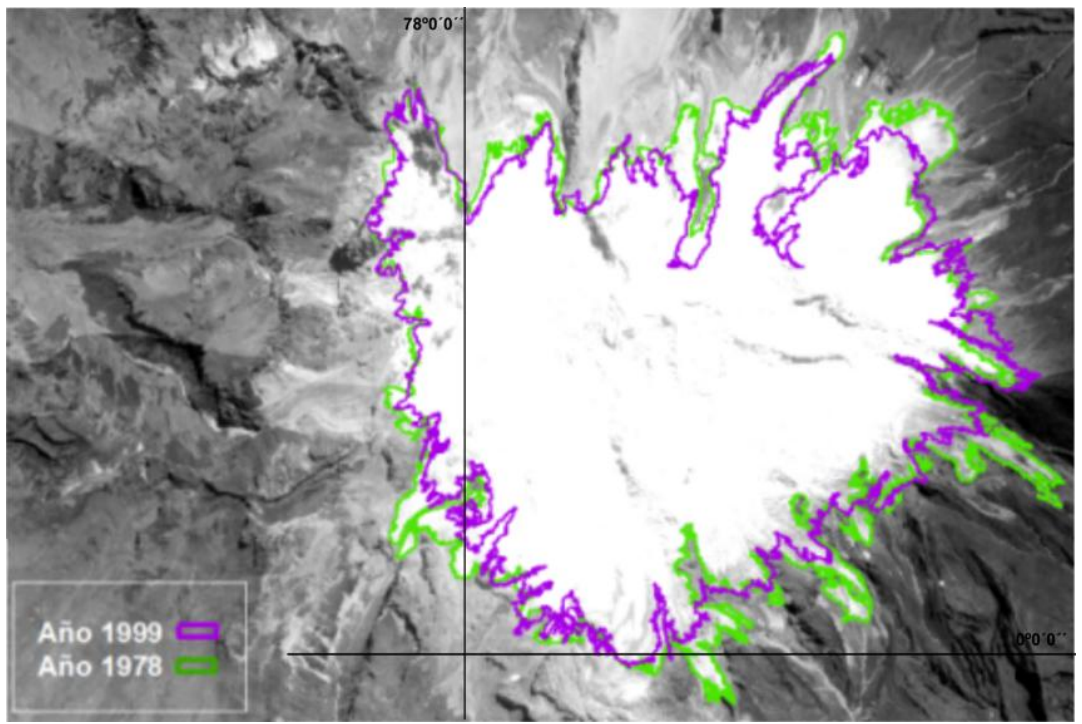

Figura 4. Retroceso del nevado Cayambe, 1978-1999, mediante fotografías aéreas.

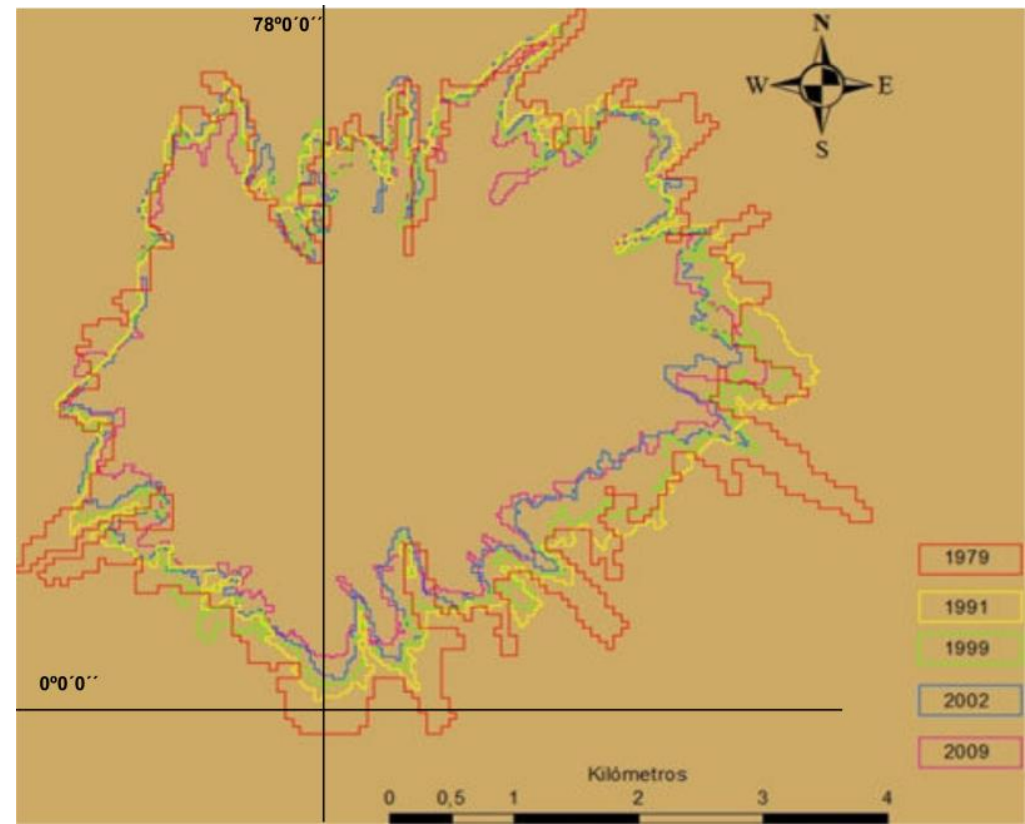

Figura 5. Retroceso del nevado Cayambe, 1979-2009, mediante imágenes satelitales.

Si se realiza una comparación con los estudios realizados en otros casquetes glaciales del Ecuador, se puede observar que el nevado Cayambe presenta un proceso de retroceso similar para el período de tiempo analizado. Por ejemplo, el glaciar del Cotopaxi se mantuvo estable entre los años de 1956 y 1976, pero a partir de esa fecha y hasta 1997 experimentó una disminución del $30 \%$ (Jordan, 2005). Durante el período 1979-2007 el glaciar del Antisana disminuyó cerca del 37 \%, mientras que el Chimborazo lo hizo en un $33 \%$ (Cáceres, 2010). El estudio desarrollado por Collet 
Gallegos Castro, E., Brito Chasiluisa,C. Serrano Giné, D., Galárraga Sánchez, R.. (2018): “Análisis de la variación temporal y espacial de la cobertura glaciar del nevado Cayambe, Ecuador, mediante fotografías aéreas e imágenes Landsat, GeoFocus (Artículos), no 22, p. 97-113. ISSN: 1578-5157 http://dx.doi.org/10.21138/GF.577

(2010) señala que en este periodo se perdió un 40,26\% de la cobertura del Antisana, y un 37,10\% de la del Cotopaxi. Los avances realizados por Marlon Calispa (2012) confirman esta tendencia y la avanzan prácticamente una década; así, para el período 1979-2007 indican una reducción del $42 \%$ para el Cotopaxi y del $39 \%$ para el Antisana. El trabajo de Febres (2007), por su parte, cuantifica la merma de cubierta glaciar del Iliniza Sur en un $41 \%$, entre los años 1956 y 2000. Otros estudios en los Andes tropicales señalan patrones similares, aunque con valores no siempre coincidentes. En la Cordillera Blanca (Perú) Veetil (2018) valora la reducción ocurrida entre 1975 y 2016 en un $33.5 \%$; en el sistema Vilcanota-Urubamba (Perú) Drenkhan et al. (2018) apuntan una reducción del $37.3 \%$ entre 1988 y 2016; y en el Nevado Santa Isabel (Colombia) desde mitad de la década de 1990, la reducción es del $36 \%$ (Rabatel et al., 2017).

$\mathrm{Si}$ se consideran todos estos valores, parece sensato afirmar una clara tendencia a la reducción de las cubiertas glaciares de los Andes equinocciales. Con todo, conviene matizar esta afirmación pues, tal como demuestra la síntesis de Rabatel et al. (2013), dicha tendencia no demuestra un valor constante y, menos aún, homogéneo para distintos glaciares; probablemente, el mejor ejemplo de ello pueda encontrarse en el crecimiento que experimentan las masas glaciares durante años particularmente húmedos, como los asociados a episodios de La Niña, por ejemplo, para el glaciar Antisana. Existen numerosas diferencias locales y regionales (Falaschi et al., 2017; Drewes et al., 2018), y los sistemas glaciares han demostrado reaccionar de manera diferente a distintos condicionantes ambientales (Małecki et al., 2018; Rowan, 2018). Rabatel et al. (2013) afirman que los estudios sobre dinámicas de glaciares tropicales todavía se encuentran pobremente documentados y apuntan la necesidad de profundizar en esta temática. Los estudios de carácter prospectivo demuestran la utilidad de dichos análisis cuando se dispone de series de datos suficientemente importantes (Yarleque et al., 2018).

Por otra parte, conviene hacer hincapié en la variabilidad climatológica andina, que se conoce por mostrar pocas variaciones interanuales de temperatura y precipitación, pero notables oscilaciones estacionales y diarias. Las consecuencias que de ello se derivan en estudios de fotointerpretación son significativas, pues tal como apuntan Racoviteanu et al. (2008), un súbito y efímero manto nivoso puede llevar a confusión a la hora de cuantificar superficie glaciar como superficie nivo-glaciar, y arrojar resultados verídicos pero no necesariamente representativos.

En un contexto diferente, resulta interesante reflexionar en la importancia de los glaciares tropicales en tanto reservas de agua, así como su efecto inmediato en el balance hídrico del páramo andino (Serrano y Galárraga, 2015). Se conoce que los suelos del páramo son ricos en materia orgánica y desarrollan un papel decisorio en la regulación y el balance hídrico de estos ecosistemas. Aparte de su valor biofísico, los páramos desempeñan importantes funciones sociales y económicas, como por ejemplo las ligadas a la ganadería, la agricultura y la producción energética. En determinados sectores, como por ejemplo la floricultura, las demandas hídricas son muy importantes, y el estudio y correcto aprovechamiento de caudales y exfluviaciones tiene un evidente sentido económico. A modo de ejemplo se puede citar la cuenca del río Blanco, que suple de agua a los cultivos de la ciudad de Cayambe y que, precisamente, es una de las cuencas que más resiente el retroceso del glaciar (Valencia et al., 2014). 
Gallegos Castro, E., Brito Chasiluisa,C. Serrano Giné, D., Galárraga Sánchez, R.. (2018): “Análisis de la variación temporal y espacial de la cobertura glaciar del nevado Cayambe, Ecuador, mediante fotografías aéreas e imágenes Landsat, GeoFocus (Artículos), $n^{o}$ 22, p. 97-113. ISSN: 1578-5157 http://dx.doi.org/10.21138/GF.577

\subsection{Aspectos técnicos}

En el caso de las fotografías aéreas, la cubierta nubosa, particularmente cuando se encuentra localizada en los márgenes del casquete, fue causante de dificultades a la hora de precisar el límite de la masa helada. Por otro lado, las sombras creadas por grietas, crevases, rimayas, bloques ascendentes y otras irregularidades topográficas en la superficie del glaciar, también fueron susceptibles de clasificarse incorrectamente, pues en ocasiones se podían confundir con derrubios y afloramientos rocosos de distinto tipo.

En ciertas áreas, el glaciar se encuentra cubierto por detritos morrénicos, dando lugar a que dicho manto pareciera material erosionado cuando, en realidad, simplemente son derrubios superpuestos a la masa glaciada. Efectivamente, resulta complicado discriminar estos dos tipos de cubiertas mediante fotointerpretación, y la definición de las grietas del glaciar y la detección de los flujos de agua percolada resultaron de gran utilidad. Es importante notar que, a menudo, el conocimiento del área de estudio y el trabajo de campo se presentan como los únicos procedimientos con cierto grado de confiabilidad; es por ello que las técnicas de teledetección nunca deben entenderse como substitutas sino como complementarias del conocimiento directo de la realidad. Distintos estudios abogan por complementar distintos procedimientos y métodos de trabajo, así como fuentes de información (Veettil y Camp, 2017; Veettil, 2018).

Con respecto a las imágenes satelitales, cabe señalar que el área de estudio está influenciada por el régimen climático de la Amazonía, que se caracteriza por la existencia de elevados valores de humedad, manifestados por densos mantos nubosos; tal como han señalado otros estudios (Calispa, 2012), la existencia de cobertura nubosa entorpece considerablemente la identificación de las cubiertas terrestres. Nuevas generaciones de sensores de teledetección pueden ayudar a corregir estas desviaciones (Veettil, 2018). Por otra parte, en muchas zonas fue posible discriminar acumulaciones de nieve importantes, motivo por el cual resultó necesaria una corrección del contorno glaciar con el fin de eliminar polígonos que pudiesen alterar el cálculo de la superficie glaciada. En algunos casos, como por ejemplo la imagen de 1979, resulta interesante notar que no existe un rango amplio de resolución espectral y que, sin embargo, la combinación de bandas permite discriminar y delimitar cubiertas de manera exitosa. Por otra parte, cabe decir que las imágenes pertenecientes a los años de 2003 a 2009 presentan un problema de bandeado que interfiere claramente en la superficie del glaciar. Este problema se corrigió con el uso de imágenes sin ruido correspondientes a 2009, y con el apoyo auxiliar de las fotografías aéreas.

Finalmente, resulta oportuno reflexionar en la conveniencia de los vehículos no tripulados como método para recabar datos. Aunque su uso todavía es muy limitado, las posibilidades de esta tecnología son muy elevadas (Kraaijenbrink et al., 2018) y permitirían complementar fuentes documentales tradicionales (Veettil y Camp, 2017).

\section{Conclusiones}

En el año 1978 la cobertura glaciar del nevado Cayambe era de $23,85 \mathrm{~km}^{2}$, mientras que para el año 1999 este valor ha disminuido a $17,76 \mathrm{~km}^{2}$. Ello muestra una reducción del casquete glaciar del Nevado para el período 1978-1999 del 25,53 \% y del 25,58 \%, según si se considera la 
Gallegos Castro, E., Brito Chasiluisa,C. Serrano Giné, D., Galárraga Sánchez, R.. (2018): “Análisis de la variación temporal y espacial de la cobertura glaciar del nevado Cayambe, Ecuador, mediante fotografías aéreas e imágenes Landsat, GeoFocus (Artículos), no 22, p. 97-113. ISSN: 1578-5157 http://dx.doi.org/10.21138/GF.577

información proveniente de fotografías aéreas o imágenes de satélite. La tasa de reducción conjunta es del 1,21\% anual; este valor puede inducir a engaño, por el hecho de existir 10 años de diferencia entre ambas fuentes de información y no contarse con valores intermedios, pero manifiesta una tendencia evidente. Esta merma no es homogénea en todo el glaciar, y la zona sur es la que acusa pérdidas más significativas. Sin embargo, esta apreciación no se encuentra suficientemente trabajada.

Mediante el procesamiento de imágenes satelitales, se pudo obtener la superficie glaciada para los años 1979, 1991, 2002 y 2009. Para el año 1979 la superficie obtenida fue de 20,64 km², mientras que 12 años más tarde (1991) ésta era de $19,32 \mathrm{~km}^{2}$, y 8 años después (1999) de $17,94 \mathrm{~km}^{2}$. A partir de esta fecha se observa un aceleramiento del retroceso: en el año 2002 se nota un área de $16,51 \mathrm{~km}^{2}$ y en 2009 de $15,36 \mathrm{~km}^{2}$.

Durante las tres décadas analizadas (1979-2009) se estima un porcentaje de reducción del glaciar en torno al $25,58 \%$, con una tasa de retroceso anual de $0,853 \%$ o, lo que es lo mismo, $0,176 \mathrm{~km}^{2} / a n ̃ o$. Si se considera la distribución por lenguas glaciares, las mayores tasas de retroceso fueron de $0,02 \mathrm{~km}^{2} /$ año (lenguas $7,9,10$ y 15) y $0,01 \mathrm{~km}^{2} /$ año (lenguas $1,4,8,12,13,14,17$ y 19). Los mayores porcentajes de retroceso se dieron en la zona sureste $(23,22 \%)$ y noreste $(30,97 \%)$.

La disminución de los glaciares ecuatorianos es generalizada, y el nevado Cayambe muestra unos valores similares a los que se encuentran en otros casquetes equinocciales. Los resultados del Cayambe coinciden con la tendencia general de los Andes intertropicales y concuerdan con estudios realizados en el Antisana, Cotopaxi, Chimborazo, Carihuayrazo e Iliniza Sur. Sin embargo, como ya se ha apuntado, conviene ser prudente a la hora de interpretar estos valores, pues la variabilidad ambiental y la escasez de estudios sistemáticos y homogéneos dificultan realizar afirmaciones de carácter universal.

Como ya se ha notado en otras ocasiones, el uso de fotografías aéreas brinda una resolución espacial de mayor precisión para los estudios evolutivos, por bien que para la zona de estudio los fotogramas disponibles tienen una baja frecuencia temporal. Por el contrario, las imágenes Landsat proporcionaron mayor frecuencia temporal, pero menor resolución espacial. Es por ello que el uso combinado de estas dos fuentes de información resulta ser de gran utilidad.

Finalmente, conviene añadir que este estudio contribuye al conocimiento sobre los glaciares tropicales y sirve de base para futuras investigaciones acerca de las dinámicas ambientales y la disponibilidad de recursos hídricos de origen glaciar sobre el páramo andino.

\section{Agradecimientos}

Esta investigación ha sido posible gracias al apoyo económico del Programa LMI-GREATICE (Laboratorio Mixto Internacional) del IRD de Francia, al programa Prometeo de la SENESCYT del Gobierno del Ecuador, el proyecto CHORA (CSO2017-82411-P) del Ministerio de Ciencia Innovación y Universidades del Gobierno de España, y al proyecto 2017SGR22 del Departamento de Investigación y Universidades de la Generalitat de Cataluña. Igualmente, queremos manifestar 
Gallegos Castro, E., Brito Chasiluisa,C. Serrano Giné, D., Galárraga Sánchez, R.. (2018): “Análisis de la variación temporal y espacial de la cobertura glaciar del nevado Cayambe, Ecuador, mediante fotografías aéreas e imágenes Landsat, GeoFocus (Artículos), no 22, p. 97-113. ISSN: 1578-5157 http://dx.doi.org/10.21138/GF.577

nuestro agradecimiento al Dr. Marcos Villacís, Dr. Antoine Rabatel, MSc Marlon Calispa e Ing. Oswaldo Proaño, por sus acertados comentarios y sugerencias.

\section{Referencias bibliográficas}

Cáceres, B. (2010). Actualización del inventario de tres casquetes glaciares del Ecuador. Quito: Escuela Politécnica Nacional. [Documento inédito].

Calispa, M. (2012). Identificación de zonas con tendencia de cambio en el período 1987-2002, en la zona Centro-Norte del Ecuador, utilizando imágenes LANDSAT. Barcelona: Universidad Autónoma de Barcelona. [Documento inédito].

Chuvieco, E. (1990). Fundamentos de teledetección espacial. Madrid: Rialp.

Collet, M. (2010). Suivi spatio-temporel des calottes glaciaires de l'Antisana et du Cotopaxi (Équateur). Analyse par télédétection dans un contexte de changement climatique. Rennes: Université de Rennes. [Documento inédito].

Drenkhan, F.; Guardamino, L.; Huggel, C.; Frey, H. (2018). Current and future glacier and lake assessment in the deglaciating Vilcanota-Urubamba basin, Peruvian Andes. Global and Planetary Change, 169, pp. 105118.

Drewes, J.; Moreiras, S.; Korup, O. (2018). Permafrost activity and atmospheric warming in the Argentinian Andes. Geomorphology, 323, pp. 18-24.

Falaschi, D.; Bolch, T.; Rastner, P.; Lenzano, M.G.; Lenzano, L.; Lovecchio, A.; Moragues, S. (2017). Journal of Glaciology, 63 (238), pp. 258-272.

Febres, A. (2007). Análisis tempo-espacial de la cobertura nivo-glaciar del volcán Iliniza Sur. Quito: Escuela Politécnica Nacional. [Documento inédito].

Felicísimo AM. (1994). Modelos digitales del terreno: introducción y aplicaciones en las ciencias ambientales. Oviedo: Pentalfa Ediciones.

Fernández, F. (2000). Introducción a la fotointerpretación. Barcelona: Ariel.

Francou, B.; Cáceres, B.; Villacís, M.; Basantes, R.; Maisincho, L.; Galárraga, R.; Romero, J.C. (2011). Analizando el cambio climático a partir de los glaciares del Ecuador. Quito: IRD, SENESCYT, EPMAPS, INAMHI, EPN.

Galicia L.; García-Romero, A. (2007). "Land Use and Land Cover Change in Highland Temperate Forest in the Izta-Popo National Park, Central Mexico". Mountain Research and Development, 27, 1, pp. 48-57.

Jaramillo, S. (2012). Evolución Glaciar en la Vertiente Norte del Volcán Cotopaxi. Madrid: Universidad Complutense de Madrid. [Documento inédito].

Jordan, E.; Ungerechts, L.; Caceres, B.; Penafiel, A.; Francou,B. (2005). "Estimation by photogrammetry of the glacier recession on the Cotopaxi Volcano (Ecuador) between 1956 and 1997”. Hydrological Sciences Journal, 50, pp. 949-961. 
Gallegos Castro, E., Brito Chasiluisa,C. Serrano Giné, D., Galárraga Sánchez, R.. (2018): “Análisis de la variación temporal y espacial de la cobertura glaciar del nevado Cayambe, Ecuador, mediante fotografías aéreas e imágenes Landsat, GeoFocus (Artículos), no 22, p. 97-113. ISSN: 1578-5157 http://dx.doi.org/10.21138/GF.577

Kraaijenbrink, P.D.A.; Shea, J.M.; Litt, M.; Steiner, J.F.; Treichler, D.; Koch, I.; Immerzeel, W.W. (2018). Mapping surface temperatures on a debris-covered glacier with an unmanned aerial vehicle. Frontiers of Earth Science, 6 (64), pp. 1-19.

Małecki, J.; Lovell, H.; Ewertowski, W.; Górski, Ł.; Kurczaba, T.; Latos, B.; Miara, M.; Piniarska, D.; Płocieniczak, J.; Sowada, T.; Spiralski, M.; Warczachowska, A.; Rabatel, A. (2018). The glacial landsystem of a tropical glacier: Charquini Sur, Bolivian Andes. Earth surface processes and landforms, 43, pp. 2584-2602.

Martín, J. (1999). Fotointerpretación y fotogrametría. Madrid: universidad Politécnica de Madrid.

Mitchell, A. (2005). The ESRI Guide to GIS analysis, II. Redlands: Esri Press.

Montero, I. (2010). En el vértice del Ecuador: el descubrimiento del sitio a más altitud en el globo terráqueo por donde cruza la línea ecuatorial. Ciudad de México: Am\&Am.

Rabatel, A.; Ceballos, J.L.; Micheletti, N.; Jordan, E.; Braitmeier, M.; González, J.; Mölg, N.; Ménégoz, M.; Huggel, C.; Zemp, M. (2018). Toward an imminent exticntion of Colobian glaciers? Geografiska Annaler: Series A, Physical Geography, 100 (1), pp. 75-95.

Rabatel ; Francou, B. ; Soruco, A. ; Gómez, J. ; Cáceres, B. ; Ceballos, J.L. ; Basantes, R. ; Vuille, M.; Sicart, J-E.; Higgel, C.; Scheel, M.; Lejeune, Y.; Arnaud, Y.; Collet, M.; Condom, T.; Consoli, G.; Favier, V.; Jomelli, V.; Galárraga, R.; Ginot, P.; Maicincho, L.; Mendoza, J.; Ménégoz, M.; Ramírez, E.; Ribstein, P.; Suárez, W.; Villacís, M.; Wagnon, P. (2013). "Current state of glaciers in the tropical Andes: a multi-century perspective on glacier evolution and climate change", The Cryosphere, 7, pp. 81-102.

Racoviteanu, A.; Paul, F.; Raup, B.; Khalsa, S.; Armstrong, R. (2008). Challenges and recommendations in mapping of glacier parameters from space: results of the 2008 Global Land Ice Measurements from Space (GLIMS) workshop. Boulder, Colorado.

Rowan, A. (2018). Mountain glaciers under a changing climate. Geology Today, 34 (4), pp. 134139.

Samaniego P.; Eissen J.; Monzier M.; Robin C.; Alvarado A.; Yepes H. (2004). Series los peligros volcánicos en el Ecuador: Los peligros volcánicos asociados al Cayambe. Quito: Corporación Editora Nacional.

Samaniego P.; Robin C.; Monzier M.; Eissen J.; Mothes P.; Hall M. (2004). El complejo volcánico Cayambe: Síntesis geológica, actividad holocénica y evaluación de los peligros volcánicos. Quito: Escuela Politécnica Nacional. [Documento inédito].

Serrano, D.; Galárraga, R. (2015). "El páramo andino: características territoriales y estado ambiental. Aportes interdisciplinarios para su conocimiento". Estudios Geográficos, LXXV, I, 278, pp. 369-393.

Smethurst, D. (2000). “Mountain Geography”. Geographical Review, 90, 1, pp. 35-56.

Tovar, C.; Seijmonbergen, A.; Duivenvoorden, J. (2013). "Monitoring land use and land cover change in mountain regions: An example in the Jalca grasslands of the Peruvian Andes". Landscape and Urban Planning, 112, pp. 40-49. 
Gallegos Castro, E., Brito Chasiluisa,C. Serrano Giné, D., Galárraga Sánchez, R.. (2018): “Análisis de la variación temporal y espacial de la cobertura glaciar del nevado Cayambe, Ecuador, mediante fotografías aéreas e imágenes Landsat, GeoFocus (Artículos), $n^{\circ}$ 22, p. 97-113. ISSN: 1578-5157 http://dx.doi.org/10.21138/GF.577

Valencia, R.; Serrano, D.; Galárraga, R. (2014). "Cambios de uso del suelo en cuencas alto andinas y consecuencias en la oferta hídrica. Caso de estudio microcuenca del río Blanco, páramos del Nevado Cayambe, Ecuador.", Revista EPN, 34, 1, pp. 1-9.

Veettil, B. (2018). Glacier mapping in the Cordillera Blanca, Peru, tropical Andes, using Sentinel-2 and Landsat data. Singapore Journal of Tropical Geography, 39, pp. 351-363.

Veettil, B.; Kamp, U. (2017). Remote sensing of glaciers in the tropical Andes: a review. International Journal of Remote Sensing, 38 (23), pp. 7101-7137.

Yarleque, C.; Vuille, M.; Hardy, D. R.; Timm, O.E.; De la Cruzm J.; Ramos, H.; Rabatel, A. (2018). Projections of the future disappearance of the Quelccaya Ice Cap in the Central Andes. Scientific Reports, 8, 15564, pp.1-10. 
